\title{
AN OVERVIEW OF INDUSTRIAL PROCESS VALIDATION OF TABLETS
}

\author{
*Sharma Chandan ${ }^{1}$, Rana $\mathrm{AC}^{2}$, Bala Rajni ${ }^{1}$, Seth Nimrata ${ }^{1}$ \\ ${ }^{* 1}$ Department of Pharmaceutics, Rayat Institute of Pharmacy, Rail Majra S.B.S Nagar, Punjab, India \\ ${ }^{2}$ Department of Pharmacology, Rayat Institute of Pharmacy, Rail Majra S.B.S Nagar, Punjab, India
}

*Corresponding Author's E-mail: c.s1889@ymail.com

\begin{abstract}
Product quality is the mainstay of pharmaceutical industries and is derived from careful attention to a number of factors including selection of quality parts and materials, adequate product and manufacturing process design, control of the process variables, in-process and end-product testing. Process validation is an integral part of quality assurance program in industries. By validating each step of production process we can assure that the final product is of best quality. This review provides information on objectives and benefits of process validation, types of process validation, major phases in validation and regulatory aspects. Guidelines and strategy for process validation of solid dosage form are also discussed.

Keywords: Quality, process variables, process validation, guidelines.
\end{abstract}

\section{INTRODUCTION}

The objective of the design and manufacture of the compressed tablet is to deliver orally the correct amount of drug in the proper form, over a period of time and in the desired location, and to have its chemical integrity protected to that point. The prime objective of any pharmaceutical plant is to manufacture products of requisite attribute and quality consistently, at the lowest possible cost. Numerous features are required to ensure product quality, such as chemical and physical stability, suitable preservation against microbial contamination if appropriate, uniformity of dose of drug, acceptability to users including prescriber and patient, as well as suitable packing, labeling, and validation ${ }^{1}$.It is through careful design and validation of both the process and process controls that a manufacturer can establish a high degree of confidence that all manufactured units from successive lots will be acceptable. Successful validation of a process may reduce the dependence upon intensive in-process and finished product testing. In most cases, end-product testing plays a major role in assuring that quality assurance goals are met; i.e., validation and end-product testing are not mutually exclusive ${ }^{2}$.

The FDA in " Guidelines on General Principles of Process Validation" defines process validation as "establishing documented evidence which provides a high degree of assurance that a specific process will consistently produce a product meeting its predetermined specifications and quality characteristics".According to EMEA, "Process validation can be defined as documented evidence that the process, operated within established parameters, can perform effectively and reproducibly to produce a medical product meeting its predetermined specifications and quality attributes"

Tablet as a dosage form comprises a mixture of active substances and excipients, usually in powder form, pressed or compacted into a solid. The excipients can include binders, glidants (flow aids) and lubricants to ensure efficient tabletting; disintegrants to promote tablet breakup in the digestive tract; sweeteners or flavors to enhance taste; and pigments to make the tablets visually attractive.
A polymer coating is often applied to make the tablet smoother and easier to swallow, to control the release rate of the active ingredient, to make it more resistant to the environment (extending its shelf life), or to enhance the tablet's appearance. The manufacturing of tablets involves extensive powder handling. The powder must be blended for uniformity and converted into the dosage form either through compression. Typical requirements include weighing, blending, mixing/granulation areas, compression, and coating areas ${ }^{4}$.

\section{OBJECTIVES OF PROCESS VALIDATION}

- In addition to the individual equipment, the manufacturing process must be validated.

- The goal is to create a robust manufacturing process that consistently produces a drug product with minimal variation that adheres to quality criteria of purity, identity, and potency.

- Engineers should draft and execute a validation plan for the manufacturing process in order to satisfy guidelines. The validation plan usually involves just a PQ section.

- Just as equipment validation, after the initial validation, major changes will result in the need for subsequent revalidation.

- Process validation will ensure a robust product which is highly reproducible over time.

\section{REASON FOR PROCESS VALIDATION}

The possible reason of performing process validation may include:

- New product or existing products as per SUPAC changes.

- Change in site of manufacturing.

- Change in batch size.

- Change in equipment.

- Change in process existing products.

- Change in composition or components.

- Change in the critical control parameters. 
- Change in vendor of API or critical incipient.

- Change in specification on input material.

- Abnormal trends in quality parameters of product through review during Annual Product Review (APR).

- Trend of Out of Specification (OOS) or Out of Trend (OOT) in consecutive batches ${ }^{5}$.

\section{Benefits of Process Validation}

- Consistent through output.

- Reduction in rejections and reworks.

- Reduction in utility cost.

- Avoidance of capital expenditures.

- Fewer complaints about process related failure.

- Reduced testing process and finished goods.

- More rapid and accurate investigations into process deviation.

- More rapid and reliable start-up of new equipment.

- Easier scale-up from development work.

- Easier maintenance of equipment.

- Improve employee awareness of processes.

- More rapid automation ${ }^{6}$.

\section{TYPES OF PROCESS VALIDATION ${ }^{7,8,9}$}

The guidelines on general principles of process validation mentions four types of validation:
A) Prospective validation
B) Concurrent validation
C) Retrospective validation
D) Revalidation

\section{Change Control}

A consistent achievement of product quality is dependent on the availability of defined/approved/ validated procedures and the application and adherence to these procedures by trained personnel. In the event that any change is to be introduced into the production operation, it is important to evaluate its potential impact and where necessary provide appropriate evaluation and/or actions. Written procedures should be in place to describe the actions to be taken if a change is proposed to a product component, process equipment, process environment, processing site, method of production or testing or any other change that may affect product quality or support system operations. Any proposals for changes should be drafted, reviewed, and approved by the appropriate organizational units, and reviewed and approved by the quality control unit ${ }^{7,10}$.

\section{Major Phases in Validation: ${ }^{11,12}$}

Phase 1: Pre-Validation Phase or the Qualification Phase

Phase 2: Process Validation Phase (Process Qualification phase)

Phase 3: Validation Maintenance Phase

\section{THE REGULATORY BASIS FOR PROCESS VALIDATION}

The concept of process validation from its beginnings in the early 1970s through the regulatory aspects associated with current good manufacturing practice (cGMP) regulations and the application thereof to various analytical, quality assurance, pilot plant, production, and sterile product and solid dosage forms considerations.

In the early 1990s, the concept of preapproval inspection (PAI) was born and had as one of its basic tenets the assurance that approved validation protocols and schedules were being generated and that comprehensive development, scale-up, and biobatch and commercial batch validation data were required in order to achieve a successful regulatory PAI audit. There are several important reasons for validating a product and/or process.

First, manufacturers are required by law to conform to cGMP regulations. Second, good business dictates that a manufacturer avoids the possibility of rejected or recalled batches. Third, validation helps to ensure product uniformity, reproducibility, and quality.

Although the original focus of validation was directed towards prescription drugs, the FDA Modernization Act of 1997 expanded the agency's authority to inspect establishments manufacturing over-the-counter (OTC) drugs to ensure compliance with cGMP.

Once the concept of being able to predict process performance to meet user requirements evolved, FDA regulatory officials established that there was a legal basis for requiring process validation. The ultimate legal authority is Section 501(a)(2)(B) of the FD\&C Act, which states that a drug is deemed to be adulterated if the methods used in, or the facilities or controls used for, its manufacture, processing, packing, or holding do not conform to or were not operated or administrated in conformity with cGMP. The cGMP regulations for finished pharmaceuticals, 21 CFR 210 and 211, were promulgated to enforce the requirements of the act. FDA has the authority and responsibility to inspect and evaluate process validation performed by manufacturers. The cGMP regulations for validating pharmaceutical (drug) manufacturing require that drug products be produced with a high degree of assurance of meeting all the attributes they are intended to possess (21 CFR 211.100(a) and $211.110(\mathrm{a}))^{12,13,14,15}$

\section{STRATEGY FOR INDUSTRIAL PROCESS VALIDATION OF SOLID DOSAGE FORMS}

The strategy selected for process validation should be simple and straightforward. The following five points gives strategy for process validation:

- The use of different lots of raw materials should be included. i.e., active drug substance and major excipients.

- Batches should be run in succession and on different days and shifts (the latter condition, if appropriate).

- Batches should be manufactured in the equipment and facilities designated for eventual commercial production.

- Critical process variables should be set within their operating ranges and should not exceed their upper and lower control limits during process operation. Output responses should be well within finished product specifications.

- Failure to meet the requirements of the Validation protocol with respect to process input and output

CODEN (USA): JDDTAO 
control should be subjected to process requalification and subsequent revalidation following a thorough analysis of process data and formal discussion by the validation team. $^{12,13}$

\section{GUIDELINES FOR PROCESS VALIDATION OF SOLID DOSAGE FORMS}

Numerous factors should be considered when developing and validating solid dosage forms. As a means of providing a broad overview of these validation criteria, the following checklist/guideline as in Table 1, is provided for tablets and dry-filled capsules for inclusion in an in depth validation program. Some of these unit operations will not be applicable for every solid dosage form (e.g., direct compression tablets and uncoated tablets).

Table 1: Check list of Validation and Control Documentation

\begin{tabular}{|l|l|l|}
\hline S.N. & Selection of cGMP & Validation and Control Documentation \\
\hline 1. & Introduction & Establishing of QA \& PV functions \\
\hline 2. & Organization and personnel & Establishment and facility installation and qualification \\
\hline 3. & Buildings and facilities & $\begin{array}{l}\text { Plant and facility installation qualification } \\
\text { Maintenance and sanitation } \\
\text { Microbial and pest control }\end{array}$ \\
\hline 4. & Equipment in-process & $\begin{array}{l}\text { Incoming components } \\
\text { Manufacturing non-sterile products }\end{array}$ \\
\hline 5. & Air and water quality & Process control systems (instruments and computers) \\
\hline 6. & Control of raw material, ind and vacuum handling. \\
\hline 7. & material, product & Depyrogenation, sterile packing, filling, and closing. \\
\hline 8. & Packing and labeling controls & Facilities \\
\hline 9. & Holding and distribution & Analytical methods \\
\hline 10. & Laboratory controls & Computer systems \\
\hline 11. & Records and reports & Batch processing \\
\hline 12. & Returned and salvage drug products & \\
\hline
\end{tabular}

PROTOCOL FOR PROCESS VALIDATION:

The protocol for process validation is given from the tables $2,3,4 \& 5$ as follows:

Table 2: Protocol for title page in industry

\begin{tabular}{|l|l|}
\hline \multicolumn{2}{|c|}{ Name of the company } \\
\hline \multicolumn{2}{|c|}{ Process validation protocol } \\
\hline Product: & Page No. : 1 of $\ldots \ldots .$. \\
\hline Protocol No. : & Version No. : \\
\hline Product name : & \\
\hline Label claim : & \\
\hline Master Formula Record (MFR) No. : & \\
\hline Batch Manufacturing Record (BMR) No. : & \\
\hline Effective Date : & \\
\hline
\end{tabular}

Table 3: Protocol approval

\begin{tabular}{|l|l|l|l|l|l|}
\hline & Prepared By & \multicolumn{3}{|c|}{ Checked by } & Approved by \\
\hline Signature & & & & & \\
\hline Date & & & & & \\
\hline Name & & & & & \\
\hline Department & $\begin{array}{l}\text { Quality Assurance (QA)/Research and } \\
\text { development (R\&D) }\end{array}$ & R \& D & Production & Quality Control Head - QA & Hen \\
\hline
\end{tabular}


Table 4: Table of Contents

\begin{tabular}{|c|l|l|}
\hline S. No. & \multicolumn{1}{|c|}{ Title Page No. } \\
\hline 1 & Protocol Approval Sheet & \\
\hline 2 & Table of contents & \\
\hline 3 & Objective & \\
\hline 4 & Scope & \\
\hline 5 & Validation term and responsibility & \\
\hline 6 & Steps for validation and acceptance criteria & \\
\hline 7 & Process flow chart & \\
\hline 8 & Procedure & \\
\hline 9 & Form - A : Review of raw material/packing material & \\
\hline 10 & Form - B : Evaluation of active raw material & \\
\hline 11 & Form - C : Evaluation of inactive raw material & \\
\hline 12 & Form - D : Qualification of equipment & \\
\hline 13 & Form - E : Test instrument calibration & \\
\hline 14 & Form - F : Dry mixing & \\
\hline 15 & Sampling point diagram of RMG & \\
\hline 16 & Form - G : Wet mixing & \\
\hline 17 & Form - H : Drying & \\
\hline 18 & Sampling point diagram of FBD & \\
\hline 19 & Form - I : Lubrication & \\
\hline 20 & Sampling point diagram of RMG & \\
\hline 21 & Form - J : Compression & \\
\hline 22 & Form - K : Coating & \\
\hline 23 & Form - L : Bulk packing & \\
\hline 24 & Re validation criteria & \\
\hline 25 & Change control & \\
\hline 26 & Stability & \\
\hline 27 & Deviations & \\
\hline 28 & Conclusion & \\
\hline 29 & Report and Approval & \\
\hline & & \\
\hline
\end{tabular}

Table 5: Validation team and Responsibilities

\begin{tabular}{|l|l|l|}
\hline Department & \multicolumn{1}{|c|}{ Designation } & \multicolumn{1}{c|}{ Responsibility } \\
\hline $\begin{array}{l}\text { Research and } \\
\text { development }\end{array}$ & Executive/Officer & $\begin{array}{l}\text { To coordinate the entire validation process by scheduling meetings and } \\
\text { discussions with production, quality control and quality assurance. } \\
\text { Preparation of preliminary validation protocol, master formula record, } \\
\text { monitoring the process, compiling and analyzing data and test results and } \\
\text { preparing the final report. To review the preliminary validation documents. }\end{array}$ \\
\hline Quality assurance & Officer & $\begin{array}{l}\text { To coordinate the entire validation process by scheduling meetings and } \\
\text { discussions with the team. } \\
\text { Preparation of validation protocol, monitoring the process, compiling and } \\
\text { analyzing data and test results and preparing the final report. } \\
\text { To review of validation documents. }\end{array}$ \\
\hline Production & Officer & $\begin{array}{l}\text { To participate in performing the validation steps during manufacturing } \\
\text { processes. } \\
\text { To assist in collection of data. }\end{array}$ \\
\hline Quality control & Officer & To test and report the test results \\
\hline Quality assurance & General manager & $\begin{array}{l}\text { To approve the process validation protocol and report. } \\
\text { To review of validation documents. } \\
\text { To approve the process. }\end{array}$ \\
\hline
\end{tabular}

\section{STEPS FOR VALIDATION AND ACCEPTANCE CRITERIA}

The following steps (Table 6) are used in industry for validation of tablets in wet granulation process. ${ }^{12,16}$ 
Table 6: Steps for validation and acceptance criteria in wet granulation process

\begin{tabular}{|c|c|c|c|c|}
\hline S.N. & Steps & Control Variable & $\begin{array}{l}\text { Critical Parameters } \\
\text { to be checked }\end{array}$ & Acceptance criteria \\
\hline \multirow[t]{2}{*}{1} & \multirow[t]{2}{*}{ Dry mixing } & Time & Mixing time & Mixing time:..........min \\
\hline & & Impeller speed & Mixing speed & $\begin{array}{l}\text { Impeller speed: } \\
\text {...(slow/medium/high) } \pm 5 \text { RPM. } \\
\text { Content uniformity : } 90 \%-110 \% \\
\text { RSD : } \pm 5 \%\end{array}$ \\
\hline \multirow[t]{2}{*}{2} & \multirow{2}{*}{$\begin{array}{l}\text { Binder } \\
\text { preparation and } \\
\text { addition. }\end{array}$} & Time & \multirow{2}{*}{$\begin{array}{l}\text { Mode and time of } \\
\text { addition }\end{array}$} & \multirow[t]{2}{*}{ Depending up on the formulation. } \\
\hline & & $\begin{array}{l}\text { Temperature, } \\
\text { solvent used }\end{array}$ & & \\
\hline 3 & $\begin{array}{l}\text { Drying Inlet/outlet } \\
\text { temperature \& time }\end{array}$ & $\begin{array}{l}\text { Inlet/outlet } \\
\text { temperature \& } \\
\text { Drying time }\end{array}$ & $\begin{array}{l}\text { Initial drying:....... }{ }^{\circ} \mathrm{C} \\
\text { Drying time: } \\
\text {......min. }\end{array}$ & $\begin{array}{l}\text { Final drying }: \ldots \ldots .{ }^{\circ} \mathrm{C} \pm 5^{\circ} \mathrm{C} \\
\text { Loss on drying }: \ldots \ldots \ldots \ldots \% \text { below } 3 \% \\
\text { or depending } \\
\text { on formulation }\end{array}$ \\
\hline \multirow[t]{2}{*}{4} & \multirow[t]{2}{*}{ Lubrication } & Time & \multirow{2}{*}{$\begin{array}{l}\text { Mixing time and } \\
\text { speed }\end{array}$} & \multirow{2}{*}{$\begin{array}{l}\text { Mixing time: ........min. } \\
\text { Speed slow: .......rpm. } \\
\text { Content uniformity : } \\
\text { Physical parameters - for information. }\end{array}$} \\
\hline & & $\begin{array}{l}\text { Blender/granulator } \\
\text { speed }\end{array}$ & & \\
\hline 5. & Compression & $\begin{array}{l}\text { Pressure and turret } \\
\text { speed }\end{array}$ & $\begin{array}{l}\text { Machine speed and } \\
\text { compression } \\
\text { pressure }\end{array}$ & $\begin{array}{l}\text { Average weight: } \mathrm{mg} \pm 5 \%, 7.5 \%, 10 \% \text {. } \\
\text { Uniformity of weight } \mathrm{mg}: \\
\text { Thickness : ...........mm } \\
\text { Hardness : .....KN or Kg/cm } 2 \\
\text { Disintegration time: } \mathrm{NMT} \ldots \ldots \mathrm{min} . \\
\text { Friability : NMT.......\%w/w } \\
\text { Assay : As per the label claim } \\
\text { Dissolution:..............\% }\end{array}$ \\
\hline 6. & Coating & $\begin{array}{l}\text { Pan speed and spray } \\
\text { rate }\end{array}$ & $\begin{array}{l}\text { Pan speed } \\
\text { Inlet \& outlet } \\
\text { temperature } \\
\text { Spray rate }\end{array}$ & $\begin{array}{l}\text { Average weight }: \ldots \ldots \mathrm{mg} \pm 5 \% \\
\text { Weight of } 20 \text { tablets }: \ldots \ldots \mathrm{mg} \\
\text { Thickness }: \ldots \ldots . . \mathrm{mm} \\
\text { Disintegration time: NMT....min. } \\
\text { Assay : As per the label claim } \\
\text { Dissolution: .............\% }\end{array}$ \\
\hline
\end{tabular}

\section{INDUSTRIAL PROCESS EVALUATION AND SELECTION FOR TABLETS}

Determine the unit operations needed to manufacture the tablets.

\section{Mixing or Blending}

Mixing or blending ensures production of uniform mixture of active pharmaceutical ingredients and excipients that do not segregate post blending. So this step is carefully scrutinized and validated. Parameters to consider:

- Mixing or blending technique

- Mixing or blending speed

- Mixing or blending time:

- Drug uniformity

- Excipient uniformity

- Equipment capacity/load .

\section{Wet Granulation}

Different types of wet granulation techniques can be used such as low shear (e.g., Hobart), high shear (e.g., Diosna, GEI-Collette) or fluid bed (e.g., Glatt, Fluid Air). Each technique will produce granules with different physical properties and will require monitoring of different processing parameters. Wet granulation parameters to be considered during development and validation are:

- Binder addition
- Binder concentration

- Amount of binder solution/granulating solvent

- Binder solution/granulating solvent addition

- Mixing time

- Granulation end point

\section{Wet Milling}

The wet granulation might need to be milled to break up the lumps and enhance drying of the granulation. Wet granules that have a wide aggregate range can lead to inefficient drying (long drying times and partially dried large granules or lumps).

Factors to consider are:

- $\quad$ Equipment size and capacity

- Screen size

- Mill speed

- Feed rate

\section{Drying}

The type of drying technique (e.g., tray, fluid bed, and microwave) required for the formulation needs to be determined and justified. The type of technique may be dependent on such factors as drug or formulation properties and equipment availability. Changing dryer techniques could affect such tablet properties as hardness, disintegration, dissolution, and stability. The optimal 
moisture content of the dried granulation needs to be determined. High moisture content can result in tablet picking or sticking to tablet punch surfaces and poor chemical stability as a result of hydrolysis.An over dried granulation could result in poor hardness and friability. Moisture content analysis can he performed using the conventional loss-on-drying techniques or such state-ofthe-art techniques as near infrared (NIR) spectroscopy.

Factors to be considered are:

1. Inlet/outlet temperature

2. Airflow

3. Moisture uniformity

4. Equipment capability/capacity

\section{Milling}

The milling operation will reduce the particle size of the dried granulation. The resultant particle size distribution will affect such material properties as flow, compressibility, disintegration, and dissolution. An optimal particle size/size distribution for the formulation will need to be determined.

Factors to consider in milling are:

- Mill type

- Screen size

- Mill speed

- Feed rate

\section{Lubrication}

Lubricants are added to reduce the friction during tablet ejection between the walls of the tablet and die cavity in which the tablet was formed. Factors like amount of lubricant added, grade of lubricant used, compatibility with other ingredients and mixing time must be considered.

\section{Tablet Compression}

Compression is a critical step in the production of a tablet dosage form. The materials being compressed will need to have adequate flow and compression properties. The material should readily flow from the hopper onto the feed frame and into the dies. Inadequate flow can result in "rat holing" in the hopper and/or segregation of the blend in the hopper/feed frame. This can cause tablet weight and content uniformity problems. As for the compressibility properties of the formulation, it should be examined on an instrumented tablet press. Factors to consider during compression are as follows:

- Tooling

- Compression speed

- Compression/ejection force

The following in-process tests should be examined during the compression stage:

- Appearance

- Hardness

- Tablet weight

- Friability

- Disintegration
- Weight uniformity

\section{Tablet Coating}

Tablet coating can occur by different techniques (e.g., sugar, film, or compression). Film coating has been the most common technique over recent years and will be the focus of this section. Key areas to consider for tablet coating include the following:

- Tablet properties

- Equipment type

- Coater load

- Pan speed

- Spray guns:

- Tablet flow

- Inlet/outlet temperature and airflow

- Coating solution

- Coating weight

- Residual solvent level

\section{In-process tests}

- Moisture content of "dried granulation"

- Granulation particle size distribution

- Blend uniformity

- Individual tablet weight

- Tablet hardness

- Tablet thickness

- Disintegration

- Impurity profile

\section{Finished product tests}

- Appearance

- Assay

- Content uniformity

- Tablet hardness

- Tablet friability

- Impurity profile

- Dissolution

These key test parameters are the yardsticks by which the major processing variables in solid dosage forms are evaluated. Some processing variables are:

- Mixing time and speed in blenders and granulators

- Solvent addition rates in granulators

- Time, temperature, and airflow conditions in dryers and coaters

- Screen size, feed rate, and milling speed in mills

- Machine speed and compression force in tablet presses

Process validation testing is generally done on the first three batches of product made in production-size equipment. Revalidation testing is only done when a "significant" change has occurred. A significant change is one that will alter the in-process or final product specification established during the validation program or a change in formula, process, or equipment. ${ }^{12,17,18}$

Basic flowchart for the validation of new and existing processes of tablet manufacturing is shown in Figure1 and Figure $2^{19}$. 


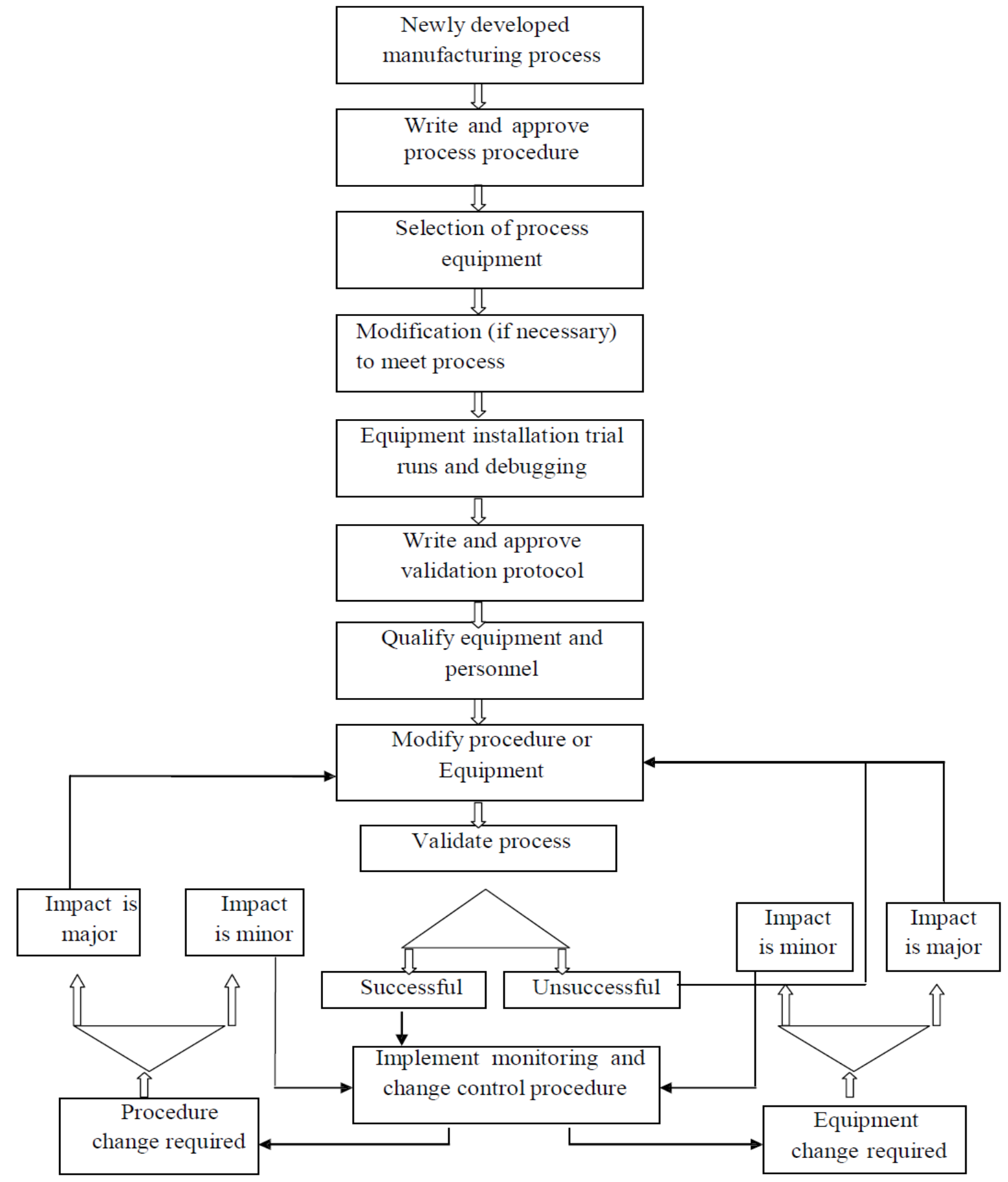

Figure 1: Validation of new processes 


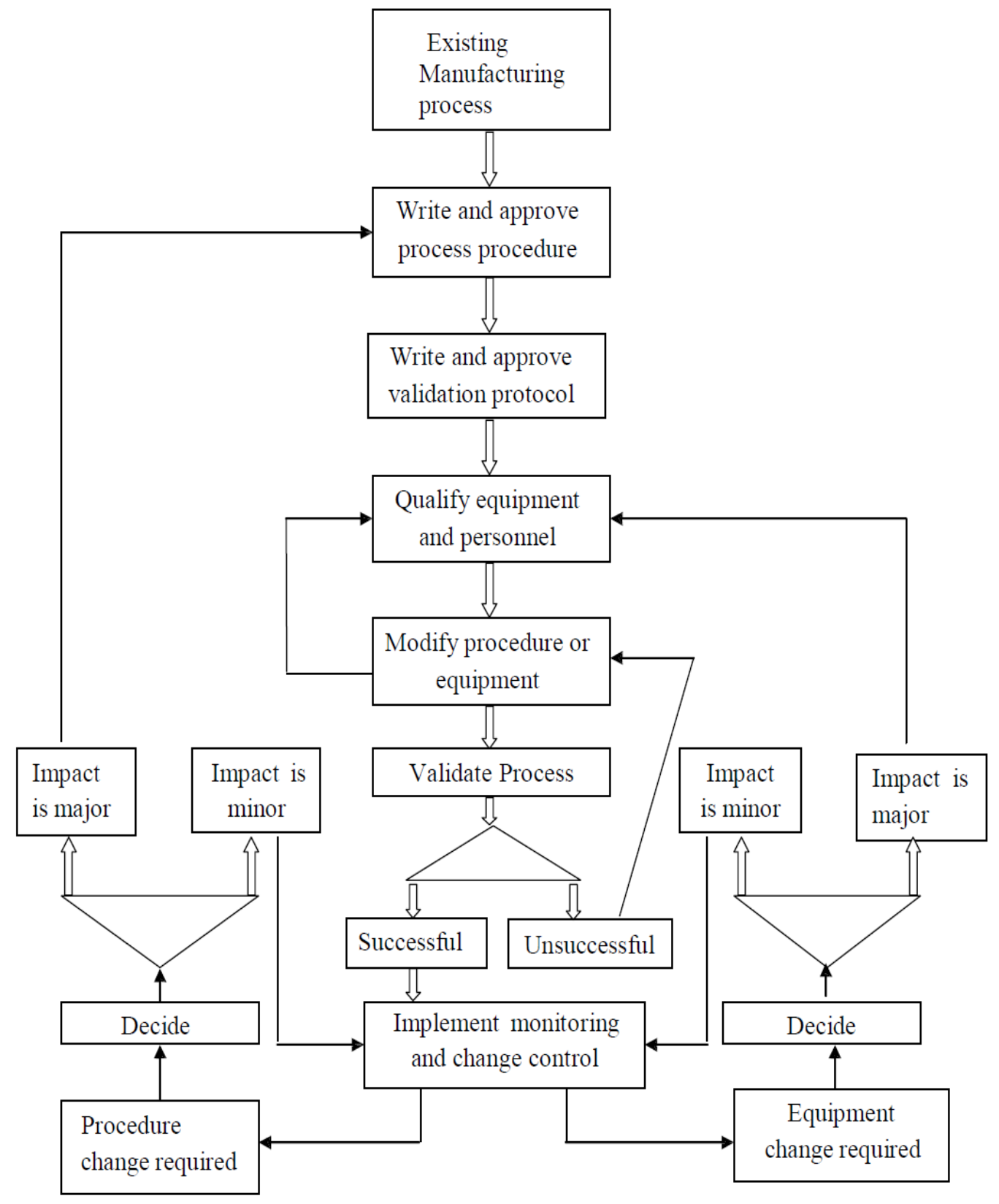

Figure 2: Validation of existing processes

\section{ANNUAL PRODUCT REVIEW}

Annual Product Quality Review is an annual quality review of licensed medicinal product which is conducted with the objective of verifying the consistency of the existing process, the appropriateness of current specifications for both starting materials and finished product to highlight any trends and to identify product and process improvements.

The Annual Product Quality review (APQR) is an effective quality improvement tool to enhance the consistency of the process and the overall quality of the product. The PQR will capture a broader view of product data, capturing trends and will help determine the need for revalidation and changes, if any.

The GMPs necessitate annual evaluation of quality standards of a drug product to determine the need for adjustments in drug product specifications, manufacturing and control procedures. Subpart J of 21 CFR 211.180 mandates establishing a written procedure for the Annual Product Review process, while, and recommends review of a representative number of approved as well as rejected batches.

The Product Quality Review Report should contain at least the following details:

- A review of starting materials and product contact primary packaging materials used for the product, especially those from new sources.

- A review of critical in-process controls and finished product results

- A review of all batches that failed to meet established specification(s) and their investigation

- A review of all significant deviations or nonconformances, their related investigations, and the 
effectiveness of resultant corrective and preventive actions taken

- A review of all changes carried out to the processes or analytical methods

- A review of Marketing Authorization variations submitted/granted/refused, including those for third country (export only) dossiers

- A review of the results of the stability monitoring programme and any adverse trends

- A review of quality-related product returns, complaints and recalls and the investigations performed at the time

- A review of adequacy of any other previous product process or equipment corrective actions

- For new marketing authorizations and variations to marketing authorizations, a review of post-marketing commitments

- The qualification status of relevant critical equipment and utilities, e.g. HVAC, water, compressed gases, etc. $^{20}$

\section{CONCLUSION}

It can be stated that process validation is major requirement of cGMPs regulation for the process efficiency and sturdiness from the review validation data on pharmaceutical process validation and process control variables of tablets manufacturing processes in industry and it is the full fledged quality attributing tool for the pharmaceutical industries. Validation is the commonest word in the areas of drug development, manufacturing and specification of finished products. It also renders reduction

\section{REFERENCES}

1. Aulton M. E., pharmaceutics, the science of dosage form design, international edition, second edition, Churchill Livingston (Elsevier), 2006; 1

2. Nash, R. A., Introduction. In: R. A. Nash, A. H. Wachter, Pharmaceutical Process Validation, Vol.129, An International 3rd Edition, Revised and Expanded, Marcel Dekker, New York, March 2003; 17-18.

3. Guidance for Industry: Process Validation: General Principles and Practices. U.S. Department of Health and Human Services, Food and Drug Administration, Center for Drug Evaluation and Research (CDER), Center for Biologics Evaluation and Research (CBER), Center for Veterinary Medicine (CVM), November 2011.

4. Michael Levin, Pharmaceutical Process Scale-Up, Marcel Dekker, Inc., New York. 2002;313.

5. Jignakumari Manubhai Tandel, Zarna R Dedania and KR. Vadalia. Review on Importance of validation IJAPBC. 2012; 1(3).

6. Rahul Paruchuri, Shagun Trivedi, Gargeyi Pavuluri, Prasanthi B and Senthil Kumar M.Process Validation of Finasteride Tablets. International journal of pharmaceutical, chemical and biological sciences. 2012; 2(1): 11-28.

7. Aleem $\mathrm{H}$, Zhao $\mathrm{Y}$, Lord $\mathrm{S}$, McCarthy $\mathrm{T}$ and Sharratt $\mathrm{P}$. Pharmaceutical process validation: an overview. J. Proc. Mech. Eng. 2003;217: 141-151.

8. Dashora K, Singh D and Saraf S. Validation - the Essential Quality Assurance Tool for Pharma Industries.2005; 3: 45-47. Cited from www.pharminfo.net.

9. Chitlange S.S, Pawar A.S, Pawar H.I, Bhujbal S.S. and Kulkarni A. A Validation.. 2006;4: 318-320.Cited from http://www.pharmainfo.net/reviews/validation.

10. Lingnau J. Optimization and Validation of Manufacturing Processes. Drug Dev. Ind. Pharm. 1989; 15: 1029-1046. in the cost linked with process monitoring, sampling and testing. The multidisciplinary approach to validation of solid dosage form must identify the product and process characteristics that must be studied and incorporate specific validation tests to ensure that that product will meet all quality, manufacturing, and regulatory requirements. The validation should start with active pharmaceutical ingredient (API) characteristics so that this material will be uniform batch after batch, providing a solid footing upon which the dosage form will be built. Scientific information obtained during the preformulation stage can form the basis for a well-designed and comprehensive validation program. The parameters chosen must be relevant indicators of a controlled process. It is not sufficient merely to devise a test and set specifications for it; rather, it is desirable to show a cause and effect relationship between the parameter tested and control of the quality and/or process output.

For the tableting procedure, the steps studied include powder blending, granulation, particle size, and lubrication with compression, coating and drug release studies. Such step-wise studies have brought light into the impact of the parameters and their interactions and increased the understanding of the respective processes and also to collect a complete and rational database for the building of validation evidence.

It is concluded from the review that pharmaceutical validation and process controls are important to assure that the drug product can meet standards for the identity, strength, quality, purity and stability.

11. Lambert J. Validation Guidelines For Pharmaceutical Dosage Forms. Health Canada / Health Products and Food Branch Inspectorate, 2004;7-15.

12. Nash R. A. and Wachter A. H. Pharmaceutical Process Validation An International Third Edition. Revised and Expanded, Marcel Dekkar, Inc., New York, 2003; 129:760-792.

13. U.S. Food and Drug Administration. Guideline on General Principles of Process Validation; U.S.FDA: Rockville, MD, May, 1987.

14. Chapman, K G, A history of validation in the United States, Part I. Pharm Tech 15(10), 1991; 82-96.

15. Tetzlaff R. F, Sheppard R. E, LeBlanc A. J, The validation story, Perspectives on the systemic GMP inspection approach and validation development. Pharm Tech March, 1993; 100116.

16. Herbert A. Lieberman, Leon Lachman, Joseph B. Schwartz, Pharmaceutical Dosage Forms Tablets, second edition, volume 3, Marcel Dekker. Inc, New York, 1990; 417-447.

17. http://www.pharmainfo.net/quality-assurance-articles/ General guidelines and principles on validation of solid, liquid and sterile-dosage forms. Cited Nov 2010.

18. http://www.pharmainfo.net/quality-assurance-articles/Process Validation: an essential process in pharmaceutical Industry.Cited March 2013.

19. Rudolph, J. S., Sepelyak, J. R., Validation of Solid Dosage Forms. In: R. A. Nash, A. H. Wachter, Pharmaceutical Process Validation, Vol.129, An International 3rd Edition, Revised and Expanded, Marcel Dekker, New York, March 2003; 209-211.

20. Guide to good manufacturing practice for medicinal products PE 009-10 (Part I). Pharmaceutical Inspection Convention, Pharmaceutical Inspection Co-operation Scheme, January 2013. 